\title{
Assessment of Hygiene Conditions in Sudanese Airlines Catering at Khartoum International Airport
}

\author{
Rania Mohammed Osman Hamid ${ }^{1} \&$ Sumia Mohammed Ahmed Khalil ${ }^{1}$ \\ ${ }^{1}$ Department of Food Hygiene and Safety, Faculty of Public and Environmental Health, University of Khartoum, \\ Khartoum, Sudan \\ Correspondence: Dr. Rania Mohamed Osman Hamid, Department of Food Hygiene and Safety, Faculty of Public \\ and Environmental Heath, P.O. Box 205, Post code 11111 Khartoum, Sudan. E-mail: \\ raniahamid2001@yahoo.com
}

Received: July 30, $2017 \quad$ Accepted: August 18, $2017 \quad$ Online Published: July 10, 2018

doi:10.5539/jfr.v7n4p149

URL: https://doi.org/10.5539/jfr.v7n4p149

\begin{abstract}
Background: Food safety has been recognized as a matter of importance to the airlines industry and airports must have the capacity to ensure a safe environment for passengers using point of entry facilities, including flight catering and other potential risks. The risk of food getting contaminated depends largely on the knowledge and practice of proper food hygiene measures among food handlers. The study aimed to assess the hygiene conditions in airlines catering services units at Khartoum Airport; to evaluate the level of knowledge and practice of food handlers towards food hygiene in addition to identify the microbial load on food handler's hands.
\end{abstract}

Methodology: Four airlines catering services units at Khartoum International Airport were studied. The data were collected by using structured questionnaire to assess food handler's knowledge on food hygiene and their practices including 100 samples (56 samples from catering 1, 22 catering 2, 12 catering 3 and 10 samples from catering 4). Observational check list was used to assess the physical characteristics and hygienic situation in airlines catering premises and food handlers. Microbiological examinations used for Total Plate Count (TPC), isolate and identification Staphylococcus aureus, Escherichia coli and salmonella. Data were analyzed using the Statistical Package for Social Sciences (version 16.0).

Results: The study showed that $56 \%$ of food handlers have higher secondary school certificate, $83 \%$ of food handlers knew causative agent of food borne disease, $72 \%$ knew when washed their work surfaces and $72 \%$ knew how to care with open lesions during food handling. Analysis showed significant difference $(\mathrm{p}=0.023)$ between respondents' knowledge and their educational level. More than half $(58 \%)$ of food handlers did not report during illness; only $42 \%$ received training in food hygiene. seventy five percent of the catering managers were not trained on food safety management system. There was statistically significant difference between trained (professional) handlers and non-trained handlers with regard to food hygiene practices $(\mathrm{P}=0.038)$. Fifty percent of catering premises were in bad situation (ventilation, cleaning, lightening, pest control) and poor hand washing facilities; only $25 \%$ of these catering have quality control system. The highest bacterial count from the hands samples was $8.5 \times 10^{6} \mathrm{CFU} / \mathrm{ml}$ and the lowest $1.2 \times 10^{6} \mathrm{CFU} / \mathrm{ml} ; 54.5 \%$ of sample tested positive for E. coli; $72.7 \%$ for $S$. aureus and $36.6 \%$ for salmonella from food handler's hands.

Conclusion: This study revealed poor sanitary conditions in airlines catering, and poor food hygiene practices of some handlers indicating higher probability of food being contaminated before service. The occurrence of indicator microorganisms in most of the hand samples indicating a need for improvement in the environment hygiene and sanitary facilities. The study recommends hygiene education to improve the knowledge and practices of food handlers.

Keywords: food hygiene, catering services, good hygiene practice, food handlers, Staphylococcus aureus

\section{Introduction}

Airline services play an important role in the world economy, huge increase in air traffic has created a need for a certain type of mass catering; the scope can vary from a small kitchen to a large catering establishment (Sheward, 2006). Flight kitchen production is a typical form of mass catering, but has some unique features distinct from food preparation in restaurants and hotels. An aircraft with limited kitchen facilities make flight catering a 
high-risk food preparation operation, the complexity of the production procedures in the flight kitchen also increases the microbiological hazards associated with this type of food preparation. Major factors affecting the hygienic quality of the food is the size of the operation, the complexity of the in-flight service, the number of airlines catered for, the number of flights serviced during the day and the duration of the flights to be serviced (Hatakka, 2000). Many flight catering now use the quality system consists of HACCP system combined with quality requirements including Standards Operating Procedures (SOP), Good Manufacturing Practice (GMP) and Good hygiene practice (GHP). The official control of flight catering depends on the national legislation of the country where the premises are located which are subject to different requirements depending on the legislation of the country, the authorities responsible for controlling flight catering operations must have good knowledge of the special features of this type of mass catering, closer co-operation between airlines, local airport health authorities and national health administrations are needed (Hattaka, 2000). Support programs are systems that must be in place to support the food safety management system; they are often described as Pre-Requisite Programs (PRP) such as: personal hygiene, training, pest control, cleaning, sanitation and equipment (ICQAP, 2010). Good Manufacturing Practices (GMPs) focus on sanitary and processing requirements necessary to assure the production of safe and wholesome food products, GMPs include provisions for food handling related to personnel, building and facilities, equipment and utensils, and production and process controls, GMPs help to control contamination by implementing good personal hygiene and effective cleaning and sanitizing procedures (Potter and Morris, 2013). Food handlers refers to people who directly touch open food as part of their work., it also includes anyone who may touch food contact surfaces or other surfaces in rooms where open food is handled, this is because they can also contaminate food by spreading bacteria for example to surfaces that food will come into contact with, e.g. work tops and food packaging before it is used. They can also contaminate other surfaces such as door handles which can then contaminate the hands of people who handle food directly for example (Shojaei et al., 2006).

Pathogens can survive for extended periods of time on many surfaces, including skin, and food handlers may therefore transmit pathogens passively from a contaminated source to a food such as cold cooked meat that is eaten without further processing they may also themselves be sources of organisms, either during the course of gastrointestinal illness or during and after convalescence, several studies confirming that poor personal hygiene by food handlers has caused outbreaks of food-borne illness caused by various pathogens, including Staphylococcus aureus, Salmonella spp., Shigella spp., enterotoxigenic Escherichia coli as well as viral agents, Hepatitis A (Jackson, 2011).

\section{Material and Method}

The study design was a descriptive cross-sectional study conducted in airlines catering in Khartoum International Airport which is located in Khartoum locality, North of Khartoum administrative unit, the study units were airlines catering establishments. Total coverage the study cover the (100) food handlers working in four air lines catering located in the study area, 100 food handlers and four managers participated in the study described in following table:

\begin{tabular}{ccc}
\hline Catering & Number of Food Handler & Number of Manger \\
\hline 1 & 56 & 1 \\
2 & 22 & 1 \\
3 & 12 & 1 \\
4 & 10 & 1 \\
Total & 100 & 4 \\
\hline
\end{tabular}

The sample size for laboratory test collected by applying the square root of $N$ plus one sampling rule:

$$
\begin{gathered}
\sqrt{\mathrm{N}+1} \\
\sqrt{100}=10+1=11
\end{gathered}
$$

Following a process of proportional allocation stratified sampling where there are four strata representing different airlines catering, stratified sampling technique applied in order to obtain a representative sample from each catering by using the following equation:

$\mathrm{ni}=\mathrm{n}$. Pi where:

ni: strata number 
$\mathrm{n}$ : sample size in stratum

$\mathrm{Pi}$ : proportion of population in stratum I, $\mathrm{Pi}=\mathrm{n} / \mathrm{N}$

N: total sample size (Sullivan, 2008).

Data was collected using the Questionnaire for assessing knowledge and practices of food handlers in the airlines catering taken into study. The questionnaire was addressed to all staff involved in food related functions in the catering, other questionnaire was administered to the managers the questions aimed at the managers were related to food safety management system. Also an observational checklist was used to assess environmental hygiene, cleanliness of buildings and personal hygiene facilities. For Bacterial Methods: Hand washes samples collected from both hands of each of the 11 food handlers by asking each one to thoroughly wash his hands in a sterile polyethylene plastic bag containing $250 \mathrm{ml}$ sterile peptone saline $(0.1 \%)$ water focusing on his finger tips, between fingers and around wrist (Fawzi,2009). The physical structure of the establishments; the sanitary facilities like hands washing facilities and food handler's personal hygiene were assessed by using observational Check list.

\section{Results}

Table 1. Socio-demographic characteristics among food handlers at airlines catering

\begin{tabular}{llll}
\hline Variables & Categories & No & \% \\
\hline Age/year & $20-30$ & 14 & 14.00 \\
& $31-40$ & 36 & 36.00 \\
& $41-50$ & 39 & 39.00 \\
& More than 50 & 11 & 11.00 \\
Gender & Total & 100 & 100.00 \\
& Male & 90 & 90.00 \\
Educational level & Female & 10 & 10.00 \\
& Total & 100 & 100.00 \\
& primary & 15 & 15.00 \\
& secondary school & 56 & 56.00 \\
& University & 17 & 17.00 \\
Experience/month & High diploma & 12 & 12.00 \\
& Total & 100 & 100.00 \\
& $>6$ & 11 & 8.8 \\
& 6-12 & 28 & 28.0 \\
& $>12$ & 72 & 72.0 \\
Job description & Total & 100 & 100.00 \\
& Cooker & 29 & 29.00 \\
& Food preparation handler & 45 & 45.00 \\
& Confectionery & 9 & 9.00 \\
& Utensils cleaner & 7 & 7.00 \\
& Total & 100 & 100.00 \\
\hline
\end{tabular}

Table 2. Reporting of illness and Actions taken by the Management

\begin{tabular}{llll}
\hline Variables & Categories & No & Percent \% \\
\hline Reporting of illness & Yes & 42 & 42.00 \\
& No & 58 & 58.00 \\
& Total & 100 & 100.00 \\
Actions taken by & Medical examination and sick leave & 67 & 67.00 \\
the Management & Only sick leave & 22 & 22.00 \\
& Only medical examination & 11 & 11.00 \\
& Total & 100 & 100.00 \\
\hline
\end{tabular}


Table 3. Knowledge on food borne disease and causative agents among food handler:

\begin{tabular}{llll}
\hline Variables & Categories & No & Percent \% \\
\hline knowledge on food borne disease & Yes & 88 & 88.00 \\
& No & 12 & 12.00 \\
& Total & 100 & 100.00 \\
causative agents of food borne disease & Bacteria & 73 & 73.00 \\
& viruses & 10 & 10.00 \\
& parasites & 2 & 2.00 \\
& Others & 3 & 3.00 \\
& Total & 100 & 100.00 \\
\hline
\end{tabular}

Table 4. Training on food hygiene received by food handlers:

\begin{tabular}{lll} 
Training & No & \% \\
\hline Yes & 58 & 58.00 \\
No & 42 & 42.00 \\
Total & 100 & 100.00 \\
\hline
\end{tabular}

Table 5. Information about Airlines catering services Buildings

\begin{tabular}{llll}
\hline Variables & Categories & No & Percent \% \\
\hline license of catering & Yes & 4 & 100.00 \\
& No & 0 & 0.00 \\
& Total & 4 & 100.00 \\
Continues hygiene inspection & Yes & 1 & 25.00 \\
& No & 3 & 75.00 \\
Application of quality control system & Total & 4 & 100.00 \\
& Yes & 1 & 25.00 \\
& No & 3 & 75.00 \\
Health authority visit & Total & 4 & 100.00 \\
& Weekly & 0 & 0.00 \\
& Monthly & 0 & 0.00 \\
& Yearly & 4 & 100.00 \\
& No visit & 0 & 0.00 \\
& Total & 4 & 100.00 \\
\hline
\end{tabular}

Table 6. Relation between educational level of worker and Knowledge about food borne disease:

\begin{tabular}{|c|c|c|c|}
\hline \multirow[t]{2}{*}{ Educational level of worker } & \multicolumn{2}{|c|}{ knowledge about causes of food borne disease } & \multirow[t]{2}{*}{ Total } \\
\hline & Yes & No & \\
\hline Primary school & 10 & 5 & 15 \\
\hline Secondary school & 51 & 5 & 56 \\
\hline University & 17 & 0 & 17 \\
\hline Higher diploma & 10 & 2 & 12 \\
\hline Total & 88 & 12 & 100 \\
\hline
\end{tabular}

Table 6 shows there was a significant relationship between educational level and knowledge about causes of food borne disease: $\mathrm{P}$-value $=0.02$ 
Table 7. training on food safety and food hygiene standards to airlines catering managers:

\begin{tabular}{llll}
\hline Variables & Categories & No & $\%$ \\
\hline Training on food safety and food hygiene standards & Yes & 1 & 25.00 \\
& No & 3 & 75.00 \\
& Total & 4 & 100.00 \\
Training organized in work place & Yes & 1 & 25.00 \\
& No & 3 & 75.00 \\
& Total & 4 & 100.00 \\
\hline
\end{tabular}

Table 8 . Hands wash facilities in airlines catering

\begin{tabular}{lllllll}
\hline \multirow{2}{*}{ Check point } & \multicolumn{1}{c}{ Yes } & \multicolumn{2}{c}{ No } & \multicolumn{3}{c}{ Total } \\
\cline { 2 - 7 } & Yes & $\mathbf{\%}$ & $\mathbf{N o}$ & $\mathbf{\%}$ & $\mathbf{N}$ & $\mathbf{\%}$ \\
\hline $\begin{array}{l}\text { Are there hand wash facilities in each area with hot water, } \\
\text { filled soap dispenser and single - use towels }\end{array}$ & 1 & 25.00 & 3 & 75.00 & 4 & 100.00 \\
Are hand washing facilities are correctly used. & 1 & 25.00 & 3 & 75.00 & 4 & 100.00 \\
\hline
\end{tabular}

Table 9. Personal hygiene and hands wash facilities:

\begin{tabular}{|c|c|c|c|c|c|c|}
\hline \multirow[t]{2}{*}{ Check point } & \multicolumn{2}{|l|}{ Yes } & \multicolumn{2}{|l|}{ No } & \multicolumn{2}{|c|}{ Total } \\
\hline & Yes & $\%$ & No & $\%$ & $\mathbf{N}$ & $\%$ \\
\hline Employees wearing clean outer garments. & 2 & 50.00 & 2 & 50.00 & 4 & 100.00 \\
\hline $\begin{array}{l}\text { Wear clean, hair nets or hair cover and wear } \\
\text { gloves during handling food. }\end{array}$ & 1 & 25.00 & 3 & 75.00 & 4 & 100.00 \\
\hline $\begin{array}{l}\text { Employees do not smoke, use tobaccos, wear } \\
\text { jewelers or eat in preparation area. }\end{array}$ & 4 & 100.00 & 0 & 0.00 & 4 & 100.00 \\
\hline Employees in good health with no open cuts or sores. & 3 & 75.00 & 1 & 25.00 & 4 & 100.00 \\
\hline Are first aid boxes clearly marked and fully stocked. & 1 & 25.00 & 3 & 75.00 & 4 & 100.00 \\
\hline
\end{tabular}

Table 10. Pest control in airlines catering

\begin{tabular}{lllllll}
\hline Check point & \multicolumn{2}{c}{ Yes } & \multicolumn{3}{c}{ No } & \multicolumn{3}{c}{ Total } \\
\cline { 2 - 7 } & Yes & $\%$ & $\mathbf{N}$ & $\boldsymbol{\%}$ & $\mathbf{N}$ & $\boldsymbol{\%}$ \\
\hline Working with a licensed pest control company. & 1 & 25.00 & 3 & 75.00 & 4 & 100.00 \\
\hline
\end{tabular}

Table 11. Microbiological analysis for catering meals

\begin{tabular}{lllllll}
\hline Check point & \multicolumn{1}{c}{ Yes } & \multicolumn{3}{c}{ No } & \multicolumn{2}{c}{ Total } \\
\cline { 2 - 7 } & Yes & $\%$ & No & $\%$ & N & \% \\
\hline Have microbiological analysis lab. & 1 & 25.00 & 3 & 75.00 & 4 & 100.00 \\
\hline
\end{tabular}

Table 12. Total Plate Count of food handlers hands sample in four catering CFU /ml

\begin{tabular}{llll}
\cline { 2 - 4 } Total bacterial count CFU/ml & Frequency & \% \\
\cline { 2 - 4 } $1.5 \times 10^{6} \mathrm{CFU} / \mathrm{ml}$ & 2 & 18.18 \\
$1.2 \times 10^{6} \mathrm{CFU} / \mathrm{ml}$ & 2 & 18.18 \\
$2.5 \times 10^{6} \mathrm{CFU} / \mathrm{ml}$ & 1 & 9.00 \\
$6.0 \times 10^{6} \mathrm{CFU} / \mathrm{ml}$ & 1 & 9.00 \\
$2.0 \times 10^{6} \mathrm{CFU} / \mathrm{ml}$ & 1 & 9.00 \\
$8.5 \times 10^{6} \mathrm{CFU} / \mathrm{ml}$ & 1 & 9.00 \\
$4.5 \times 10^{6} \mathrm{CFU} / \mathrm{ml}$ & 1 & 9.00 \\
$6.0 \times 10^{6} \mathrm{CFU} / \mathrm{ml}$ & 1 & 9.00 \\
$7.5 \times 10^{6} \mathrm{CFU} / \mathrm{ml}$ & 1 & 9.00 \\
\hline
\end{tabular}

Maximum level $=8.5 \times 10^{6} \mathrm{CFU} / \mathrm{ml}$

Minimum Level $=1.2 \times 10^{6} \mathrm{CFU} / \mathrm{ml}$ 
Table 13. Type of bacterial isolated from hands of food handlers

\begin{tabular}{lll}
\hline Type of bacterial isolated & Frequency & \% \\
\hline Escherichia coli & 6 & 54.50 \\
Staphylococcus aureus & 8 & 72.70 \\
salmonella & 3 & 36.60 \\
\hline
\end{tabular}

\section{Discussion}

This study reported the findings which assessed hygiene condition in Sudanese airlines catering, food handlers' knowledge, attitudes and practices of food hygiene, safety and regulations which are in place in studied catering Location observation at the visited catering reveled hygiene and food safety violations, only one of them (25\%) gave educational courses and trained on food hygiene to management staff The findings of the study also revealed poor sanitation conditions in the airlines catering, most of the airlines kitchens did not meet the required facility standards to provide safe food to the passengers, this mean that high risk of food borne disease may occur locally in Khartoum airport, $(75 \%)$ of the food handlers in studied catering were observed not wash their hands with soap and warm water after using doors, after handling raw food, re washing prevent cross-contamination and avoidance of post washing contamination ICQAP ( 2008) and IFSA ( 2010) recommended that Food provider must ensure that all hand washing stations are appropriately located and identified with an appropriate sign, and always accessible, clean, fully functional and well equipped with water, soap and either single use towels or a fully functional hand drying device, food provider must ensure that hand washing stations are only used for hand washing, only one catering (25\%) had complied with this requirement, according to the direct observation during the data collection time food handlers wash their hands in the food sinks in the kitchen when they come back from the toilet(25\%) this is a greater health risk especially in the event that any of the food handlers is suffering from diarrhea related infections that means the food and surfaces in the food area being contaminated similar result by Olaitan (2008) found that only (37.5\%) of the food premises visited had complied with this requirement also in a survey done by Jackson (2011) it was found that none of the hygiene facilities scored (100\%), hand wash basin facility was also being used as a food sink.

The level of personal hygiene in the studied catering needs rapid intervention from both of the responsible authorities and food handlers to ensure the safety of their food products certain hygiene practices that contribute to contamination were observed in some of the food handlers this was proved by laboratory results as most of the samples had high Total Plate Count, most of food handlers (50\%) were found wearing dirty protective clothing and $(50 \%)$ were not wear hair cover and not using gloves during the preparation of RTE food, no monitor for the frequency of change of gloves was observed this data was also complied with Sidahmed and Omer (2011) were found that $(31 \%$ )of food handler do not were gloves during food handling and $(64 \%)$ have poor personal hygiene also Boro et al (2015) reported, apron and caps were not used by most of the food handlers.

only (25\%) were working with a licensed pest control company also evidence of pest such as flies, insects and roaches was observed in $(50 \%)$ of the studied catering, the other major objective of hygienic food handling is to avoid contamination food through pest control activity, pest management in food handling requires special consideration because of the types of pest problems involved and presence of very favorable conditions for pests because of the type of work or operation involved. No microbiological analysis laboratory for testing was found on $(75 \%)$ it is recognized that without effective food quality control system it will be difficult to ensure that food are safe, quality control points of concern microbiological testing of food, food handlers, surfaces and equipments such as chopping board ,knives this result in agreement to the result done by Sid ahmed and Omer ( 2011) were reported that there is only (20\%) of the studied catering had quality control lab, also other supported study Nyamri (2013) reported that without microbial analysis and time/temperature checks of the food, it is difficult to determine the food safety. Observed in this study are supported and is in line with the inspection reports of the FDA by Stoller (2010). The probability of food contamination in these airlines catering is likely to be high due to poor sanitary conditions of the catering establishments, there are usually issues associated with the catering facilities, access and resources, these important issues which when addressed correctly would improve safe food practices and minimized health hazards from airlines catering may be minimized. the current study included 100 workers with mean age 41-50 (39\%) and work duration of more than a year was (72\%), (90\%) were males, educationally, (15\%) had primary education, $(56 \%)$ had secondary while (17\%) had university education and $(12 \%)$ higher diploma so majority were educated most of them were classified as RTE food preparation handler $(45 \%)$. the results obtained from questionnaires exhibit a high level of knowledge and assumed behaviors on the part of respondents. These results were slightly better among people who had a 
high-school educational level and for those who had worked more years in the catering sector, from this study it is clear that there is a relationship between the level of education and knowledge levels of food hygiene as it was confirmed with the Pearson's Chi Square test with the P-Value of 0.001 at 5\% significance similar result from study carried out by Abdel-Rahman et al (2014) revealed that food handlers had good knowledge on hygiene measures with a mean percentage score (76.6\%) another result is in line with the finding Chipabika ( 2014) found that there was an association between education and level of knowledge in food hygiene on other hand, some basic knowledge is defective where about half of the participants mentioned that they not reported when they are sick (58\%),FDA ( 2013) reported that management should explain to food employees the importance of reporting specific symptoms and any diagnoses or exposures to food borne illness things to be reported to management include vomiting, diarrhea, jaundice, sore throat with fever, or any exposed boil or open, infected wounds or cuts on the hands or arms, Annor and Biden (2011) noted that (40\%) of food handlers continued working while having diarrhea, while $(80 \%)$ of them would handle food during an attack of fever. the findings of this study reflected that $(75 \%)$ of managerial staff and (42\%) of food handlers have not received basic food hygiene training, any lack in this important aspect might contribute to the inability of food handlers to understand the basic principles of hand hygiene during food handling. Food hygiene training should be a priority for both managers and staff ICQAP (2010) recommended that food provider must have and follow food safety and hygiene training program also Adams and Moss (2008) said Food handlers should be trained in the basic concepts and requirements of food and personal hygiene as well as those aspects particular to the specific food-processing operation. The main reason for limiting contact between RTE foods and people's hands is to prevent the transfer of bacteria that are already present in human bodies, although the hand washing method followed by the food handlers significantly decreased bacteria counts, in present study were still high the result found that $(60 \%)$ of the samples analyzed more than limit $(<100 \mathrm{cfu} . \mathrm{ml})$ this is an indication of insufficient hand washing and sanitation, as one would expect a significantly reduced bacterial count on the workers' hands after they have cleaned and sanitized them, microorganisms are transferred to the hands in the process of handling food and through poor personal hygiene resulting in the hands being heavily contaminated with enteric pathogens results of this study revealed the unsatisfactory level of the hand hygiene among food handlers investigated and underlines the need to improve food handlers' hygiene knowledge by focusing on hand washing practices, studies supported this result by Lues and Tender (2007) found TPC was present on (98\%) of food handler's hands, Rosmawati et al (2014) found (62.0\%) In food handles' hands. Throughout the four airlines catering the study failed to find free hands from the Escherichia coli the percentage of contaminated hand washes reach $(54.5 \%)$ this can be attributed to either in efficient hand washing or post hand washing contamination similar study support the results of this study by Lues (2006) reported that Escherichia coli was isolated from (78\%) of the hand samples. The result of this study found that Staphylococcus aureus were present in $(72.7 \%)$ on the hands of food handlers samples throughout the four studied catering these findings should be a serious concern for management, as this indicates that food handlers do not comply with hand hygiene during food handling, these pathogens may be transmitted to food contaminating it and causing food-borne illnesses, in study done by Hatakka (2000) also support this study finding reported that the prevalence of Staphylococcus aureus among finish flight catering employees (9\%) according to hand sampling, other studies had a similar result by El-Shenawy et al (2014) reported infection rate with Staphylococcus aureus (38\%)) and (11\%) by Abdel-Rahman et al (2014). This result showed an association with the absence of hands washing facilities in the studied catering and the presence of the microbial contamination of hands, in general, the microbial contamination on hands of food handlers appeared higher the presence of Escherichia coli and Staphylococcus aureus on hands is an indication of poor hand hygiene, as identified during the observation phase of the data collection. Preparing food for aircraft is a highly vulnerable operation, and therefore testing carriage among food handlers is of valuable assistance in planning preventive measures, the availability of the passenger manifest can be extremely valuable for investigating in-flight disease outbreaks where more pathogenic agents might be involved.

\section{Conclusion}

The main findings of the study that assessment of the good hygienic practices and good catering practices has identified gaps with regard to status of the airlines kitchen, On location observation at the visited catering revealed hygiene and food safety violation. The findings of the study also indicate the presence of high counts of bacteria; sixty percent $(60 \%)$ on food handlers hands this indicates improper hygiene practices and improper hands washing among food handlers also the results highlighted that all samples collected from hands of food handlers in this study were contaminated with Staphylococcus, Escherichia coli and salmonella. 


\section{References}

Abdel-Rahman, S, M., Mostafa, N., \& Hakim, A. (2014). Assessment of the Knowledge, Attitude and Practice toward Food Poisoning of Food Handlers in Some Egyptian Work Sites, Egyptian Journal of Occupational Medicine, 38(1), 79-94. https://doi.org/10.21608/ejom.2014.789

Adams, M., \& Moss, M. O. (2008). Food microbiology, third edition. The Royal Society of Chemistry, Cambridge.

Annor, G., \& Baiden, E. (2011). Evaluation of Food Hygiene Knowledge Attitudes and Practices of Food Handlers in Food Businesses in Accra, Ghana. Food and Nutrition Sciences, 2(8), 830-836. https://doi.org/10.4236/fns.2011.28114

Boro, P., Soyam, V. C., Anand, T., \& Kishore, J. (2015). Physical Environment and Hygiene status at food service establishments in a tertiary care medical college campus in Delhi, Asian Journal of Medical Sciences, 6(4), 76-79.

Chipabika, E. (2014). An assessment of hygiene practices among food handlers in restaurants in Kabwe Urban District, Dissertation master, university of Zamia.

El-Shenawy, M., Tawfeek, M., El-Hosseiny, L., Farag, A., Baghdadi, H., Saleh, O., Mañes, J., \& Soriano, J. M. (2014). Cross Sectional Study of Skin Carriage and Enterotoxigenicity of Staphylococcus aureus among Food Handlers, Open Journal of Medical Microbiology, 4(1), 16-22. https://doi.org/10.4236/ojmm.2014.41003

Fawzi, M., Gomaa, N. F., \& Bakr, W. (2009). Assessment of hand washing facilities, personal hygiene and the bacteriological quality of hand washes in some grocery and dairy shops in Alexandria, Egypt, The Journal of the Egyptian Public Health Association, 84, 72-93.

FDA: Food and Drug Administration, (2013). Employee Health and Personal Hygiene Handbook, Guidance Regulation/Retail Food Protection Industry and Regulatory Assistance. U.S. Food and Drug Administration, Center for Food Safety and Applied Nutrition.

Hatakka, M. (2000). Hygienic Quality of Foods Served on Air craft, Masters Dissertation, University of Helsinki, Finland.

ICQAP: IATA Catering Quality Assurance Programme, (2008). Food Processing Safety Standards and Interpretation Guidelines, Version 2(0), Medina Foods Inc.

ICQAP: IATA Catering Quality Assurance Programme, (2010). Food Processing Safety Standards, Version 3(1), Medina Foods Inc.

IFSA: International Flight Services Association and Association of European Airlines, (2010). World Food Safety Guidelines for Airline Catering, Third version.

Jackson, L, (2011). Food Safety Management and Associated Food Handler Behaviors in A prominent South African Entertainment Facility, Master Thesis, Central University of Technology, South Africa.

Lues, J. F. (2006). Assessing food safety and associated food handling practices in street food vending, International Journal of Environmental Health Research, 16(5), 319-328. https://doi.org/10.1080/09603120600869141

Lues, J., \& Tonder, I. (2007). The occurrence of indicator bacteria on hands and aprons of food handlers in the delicatessen sections of a retail group. Food Control, 18(4), 326-332. https://doi.org/10.1016/j.foodcont.2005.10.010

Nyamri, J, (2013). Evaluation of Compliance to Food Safety Standards among Food Handlers in Selected Hospitals in Kenya, Doctoral dissertation, Kenyatta University.

Olaitan, E. A. (2008). Assessing Compliance with Food Hygiene Requirements among Urban and Sub-Urban Classified Hotels in Bauchi State, Nigeria, A thesis of Master, Kenyatta University.

Potter, E., \& Morris, J. (2013). Food borne Infections and Intoxications, Fourth edition, Elsevier Inc, USA, Publishing Ltd, London.

Rosmawati, N., Manan, W., Izani, N., \& Nurain, N. K. (2014). Evaluation of Environmental Hygiene and Microbiological Status of Selected Primary School Canteens, Environment Journal, 5(3), 110-127.

Sheward, E. (2006). Aviation food safety, John Wiley and Sons, New Jersey. 
Shojaei, H., Shooshtaripoor, J., \& Amiri, M. (2006). Efficacy of simple hand washing in reduction of microbial hand_contamination of Iranian food handlers, Food Research International, 39, 525-529. https://doi.org/10.1016/j.foodres.2005.10.007

Sidahmed, R. K., \& Omer, M. E. (2011). Catering assessment in different hotels, restaurant and an event in Khartoum State, Bachelor Dissertation, Ahfad University for Women, Sudan.

Stoller, G. (2010). FDA Inspection Report on Airline Food could pose health threat, U.S. Food and Drug Administration, USA Today Travel News Paper.

Sullivan, M. (2008). Fundamental of Statistics, Second edition, Pearson Education Inc, United States of American.

\section{Copyrights}

Copyright for this article is retained by the author(s), with first publication rights granted to the journal.

This is an open-access article distributed under the terms and conditions of the Creative Commons Attribution license (http://creativecommons.org/licenses/by/4.0/). 